\title{
Prioritizing trust in a globally distributed software engineering team to overcome complexity and make releases a non-event
}

\author{
Prasad K. Kabbur \\ Siemens Healthineers \\ Bengaluru, Karnataka, India \\ prasad.kabbur@siemens- \\ healthineers.com
}

\author{
V. S. Mani \\ Siemens Healthineers \\ Bengaluru, Karnataka, India \\ vs.mani@siemens- \\ healthineers.com
}

\author{
Juergen Schuelein \\ Siemens Healthineers \\ Forchheim, Bavaria, Germany \\ juergen.schuelein@siemens- \\ healthineers.com
}

\begin{abstract}
We share the experience of a globally distributed software development organization in addressing the performance issues resulting from the increased complexity caused by rapidly changing market demands. We discuss the challenges caused by the complexity within the teams, which were characterized by the emergence of thinking in silos, reduced morale, and accountability for overall project results, and a reduction in trust. We outline our successful approach to restore performance, which centered on fixing the trust deficit. Over time, the team progressed and went on to surpass its previous high-performance levels. Eventually, the software release process became a non-event for the team.
\end{abstract}

\section{KEYWORDS}

Global software engineering, large scale agile, trust, leadership, accountability, team building

\section{ACM Reference}

Prasad Kabbur, V. S. Mani, and Juergen Schuelein. 2020. Prioritizing trust in a globally distributed software engineering team to overcome complexity and make releases a non-event. In Proceedings of ICGSE '20: 15th IEEE/ACM International Conference on Global Software Engineering. October 5--6, 2020. Seoul, Republic of Korea, 5 pages

https://doi.org/10.1145/3372787.3390434

\section{Introduction}

This report shares the experience of a globally distributed software development organization in overcoming performance issues by prioritizing trust.

${ }^{*}$ Permission to make digital or hard copies of all or part of this work for personal or classroom use is granted without fee provided that copies are not made or distributed for profit or commercial advantage and that copies bear this notice and the full citation on the first page. Copyrights for components of this work owned by others than ACM must be honored. Abstracting with credit is permitted. To copy otherwise, or republish, to post on servers or to redistribute to lists, requires prior specific permission and/or a fee. Request permissions from Permissions@acm.org. ICGSE '20, October 5-6, 2020, Seoul, Republic of Korea

(C) 2020 Association for Computing Machinery.

ACM ISBN 978-1-4503-7093-6/20/05 _.\$15.00

https://doi.org/10.1145/3372787.3390434
The paper is structured as follows. Section 1 (this section) outlines the structure. Section 2 describes the initial setup of the team and the development methodology used. Section 3 discusses the challenges faced and approaches to identify the root causes. Section 4 describes the corrective measures, and section 5 presents the outcomes. Section 6 outlines the lessons learned.

\section{Background}

The globally distributed software development organization spread across Germany and India develops software for computed tomography (CT) systems. The systems consist of hardware subsystems and software subsystems. The organization develops software subsystems, which include 1) components of a software platform, 2) application software, and 3) CT scanner software. Most of the platform components and application software get developed in India. Global roles such as product owners, program managers are primarily based in Germany, where the hardware gets designed and developed.

To address the dependency between the software subsystems, the teams adopted an iterative methodology with one-month sprints that deliver potentially shippable increments (PSIs). The PSIs created every month are integrated with the platform software. The application software, the platform software, and the scanner software are periodically integrated and tested on the hardware to ensure a yearly release.

Following a matrix organization, the team members were grouped into functions such as product management, architecture, development, testing, and quality. Each of these functions supported different projects to ensure the milestone commitments were fully met.

The team had a proven track record in terms of delivering highquality software, on time, and within budget, which was sustained for several years. However, in 2018, the performance of team began to drop continually for about six months, which was unprecedented. 


\section{Challenges (Changes in external factor)}

The team performance had started to slip and was rapidly going downhill with an increasing number of defects. Also, teams had to continually stretch to meet the committed milestones.

An initial assessment of the situation revealed the main new challenge faced by the global team was the surge in the volatility of market demands. As a result, the requirements changed quickly and became more complex by causing greater interdependencies between the various subsystems. This meant that there were more and more features that cut across application software, the platform, and scanner software.

Managing these requirements, while ensuring conformance to stringent regulatory requirements, and the long product lifecycle of the systems, became even more difficult. Especially because it needed significantly more coordination between the teams developing the software platform, the application software, and the scanner software. Also, the software platform teams were releasing more frequently, and additional functionality was being included in the platform, which substantially increased the dependency of the application software and scanner software on the software platform.

Beyond these technical issues, behavioral symptoms were also observed. During project status review meetings (similar to Scrum of Scrums) it was noticed that the different Scrum teams were focusing only on their specific problems. There was a lack of coordinated decision-making during meetings. Also, none of the leadership roles were taking ownership and accountability for the overall results. Furthermore, Scrum teams continued to struggle in meeting milestones. Importantly, the morale of the Scrum teams had dropped considerably. Individual Scrum teams had the impression that the cause of the problem was in another team. Moreover, interactions were characterized by increased blaming. Figure 1 shows the vicious circle where the trust gets diminished due to increased complexity.

These symptoms were indicative of dysfunctions within the overall project team. To validate this assumption, we conducted a survey to understand the team dynamics. The survey questions were based on [5].

To start with the survey was conducted with individuals in leadership roles. These included people managers, architects, Scrum masters, quality mangers to name a few.

The survey results (Figure 2) showed that there were dysfunctions within the teams. According to [5], scores in the range 3-5 indicate the dysfunctions need to be addressed, whereas scores in the range 6-7 indicate dysfunctions could be a problem. Scores of 8-9 indicate dysfunctions are not a problem.

Specifically, the survey indicated there three clear dysfunctions: 1) absence of trust, 2) avoidance of accountability, and 3) inattention to results.

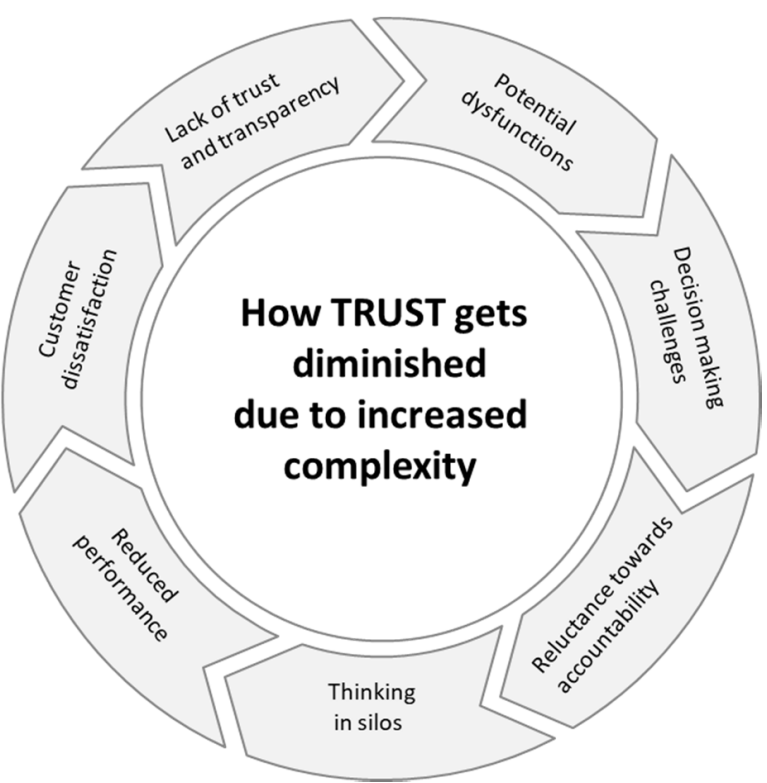

Figure 1: How trust gets diminished due to increased complexity

\section{Defining corrective measures}

The survey findings were shared with the participants. When asked if they agreed with the survey findings, the unanimous and emphatic response was 'Yes'.

They saw the main findings of the survey closely aligned with their observations of the behaviors of individuals during the project execution,

The entire leadership team was keen to address the problem. To better understand the situation, multiple one-on-one sessions were held with team members across different roles.

\begin{tabular}{|l|c|}
\hline \multicolumn{1}{|c|}{ Dysfunctions } & Score \\
\hline Absence of Trust & 5.9 \\
\hline Fear of Conflict & 7.2 \\
\hline Lack of Commitment & 6.8 \\
\hline Avoidance of Accountability & 5.7 \\
\hline Inattention to Results & 5.8 \\
\hline
\end{tabular}

Figure 2: Survey Results (indicative)

The one-on-one sessions revealed that team members perceived the work environment as 'stressful', 'divisive,' 'unproductive,' and 'tense.' Also, the morale in the team was low. These were typical characteristics of a low trust environment [12]. 
After several deliberations around the survey results, and the feedback from the one-on-one sessions, we decided to address the three dysfunctions. For each dysfunction, a series of corrective actions was defined, as described below.

\subsection{Prioritizing trust}

To address the absence of trust, we defined a series of measures to prioritize trust and foster a sense of belonging. These were: 1) creating shared vision, 2) defining a thematic goal, 3) establishing circle of safety, 4) introducing the 'disagree but commit' approach.

As a first step, we set out to create a strong team spirit. We did this by creating a shared vision of 'One CT', that is a single Computed Tomography team. The vision did create a sense of belonging, but to make the it actionable, we defined a thematic goal [13], which was 'One voice from CT with high-quality delivery on time'.

This goal articulated the desired state, namely, high-quality delivery on time, It also demanded that everyone in the organization knew the real current status of the entire project, to understand the gap between the reality and the vision.

To know the real state of the project, teams needed to feel safe in sharing the actual status, which was a challenge. So. the project leadership was urged to create a circle of safety where all team members could openly talk about the real situation.

The project leadership also recognized that achieving results alone was not enough. How the results were achieved was equally important for sustained high-performance.

To create a circle of safety, the project leadership had to demonstrate empathy with a sense of perspective. This allowed all team members to be vulnerable, encouraged teams and individuals to ask for help, declare breakdowns, and speak up without fear of retribution. It helped the Scrum teams to identify who needed support so that they could assist.

The thematic goal along with the circle of safety enabled the team to prioritize quality over the entire duration of the project, rather than only focusing on delivering the immediate milestones on time. For example, teams were no longer afraid of missing an intermediate milestone for quality reasons. as long as they could ensure quality for the final milestone.

We also introduced the 'disagree but commit' approach. All team members were free to disagree with an approach and voice their opinion. However, once a decision was collectively made all team members had to commit to the decision. Although the decisions were made collectively, they were not necessarily based on consensus.

The above measures went a long way in strengthening trust within the team. They also helped improve the morale.

\subsection{Increasing accountability}

To address the avoidance of accountability, we defined a series of measures to increase accountability. These were: 1) restructuring the organization, 2) instilling peer accountability, 3) establishing a 'results only work environment', 4) building capabilities to help team members feel accountable, 5) living agile in spirit

We had observed a lack of accountability for the overall project within the Scrum teams. While reflecting on this behavior, we realized that the legacy matrix organization was coming in the way of effective decision making for aspects concerning the overall project. For instance, the people managers were more focused on the people development and less on the project outcomes while the project managers were unclear about their role in developing people. To address this situation, we decided to reorganize to a projectized structure where there were no roles without delivery responsibility [8] to bring in greater clarity on ownership, accountability, and responsibility across all members of the project.

To instill peer accountability, we also asked the team members if they are accountable for themselves or for each other. We also asked them if they were only accountable for the deliverable committed by their Scrum team, or for the commitments made by the overall project team. Initially, the question was met with silence. Over time, after the circle of safety was experienced by the team, the team members started asking each other for help to fulfill their commitments for every sprint, when needed. Quickly, the team realized that they were accountable for each other to ensure the overall commitments were met.

We observed that in many cases the lack of accountability originated in micro-management, that is directive mode of leading [9]. We also observed the project pressures were driving managers to resort to the directive mode of leading. They were instructing their team members on how to address a topic, to ensure the immediate milestones were met. To address the lack of accountability due to micro-management, we asked the managers to foster autonomy and avoid micro-managing. The overall goal was to establish a results-only work environment [1]. The focus was on establishing an environment where the teams could focus on meeting their commitments in the best possible way.

We realized that team members were reluctant to hold themselves accountable when they did not possess necessary capabilities. For example, team members found it difficult to effectively address the complexity of features that cut across the application software, the software platform, and scanner software, and were unwilling to assume accountability. To help them overcome these technical challenges, we conducted a series of domain and application training sessions to equip them accordingly. To highlight the importance of learning and development (L\&D) we celebrated December as "L\&D month." A series of trainings were organized to address specific domain and technical aspects and team members were encouraged to attend the trainings based on their personal preferences. The trainings were well received and well attended. 


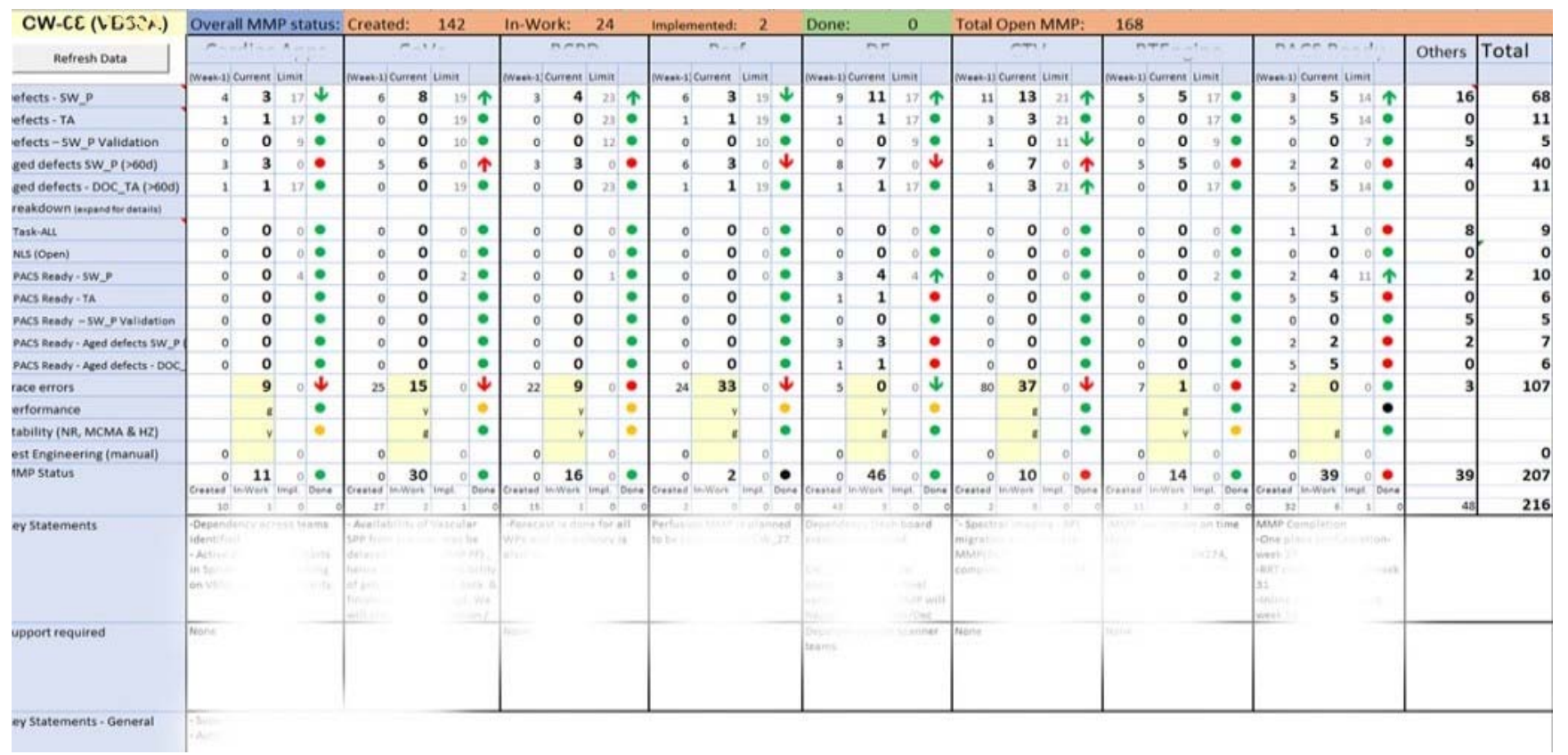

Figure 3: Project Scorecard

To encourage team members to live the agile principles in spirit and be accountable, that is not merely practice agile rituals, we started the living agile in spirit initiative. It is noteworthy that the topics of this initiative were defined and driven by the team, which reflected the already increasing accountability. For example, the team proposed stricter readiness (entry) and done-ness (exit) criteria. This meant no task in the backlog could be picked unless the stricter readiness criteria were met. Similarly, no task can be classified as done, unless it met the stricter done-ness criteria.

\subsection{Increasing attention to results}

To address the inattention to results, we defined measures to 1) dismantle thinking in silos, and 2) make results continually visible.

We recognized that the Scrum teams had started to think in silos. This meant, that they believed that if every Scrum team achieved their specific goals, the overall project would be successful. However, this was not the case. Though every Scrum team was meeting their goals, the overall project was in red. This was mainly because of the insufficient attention to prioritize dependencies of the features cutting across different sub-systems.

We were able to dismantle thinking in silos, through the efforts to instill peer accountability that got team members to collaborate across Scrum teams. Also, the steps towards a shared vision and thematic goal helped team members feel connected to a larger organization beyond their respective teams, helped reduce thinking in silos.
In addition, the Scrum teams did not have a clear view on the status of the overall project. To address this situation, we institutionalized a weekly project review where all Scrum teams were asked to share their status in terms of scorecards. As the team became more confident of sharing the real status, it helped in understanding the interdependencies between teams and reprioritizing crossfunctional features. The scorecards (Figure 3 ) proved very effective as they showed the overall status clearly, in addition to the individual team status. The scorecards and weekly project reviews helped in increasing attention to results.

\section{Outcomes}

The identified interventions helped the team in: 1) addressing the indicated dysfunctions, 2) overcoming complexity, 3) making project releases a non-event.

The outcomes of the different measures to address the dysfunctions are outlined in section 4 . These measures enabled team members to take ownership, accountability and responsibility for the results and build trusting teams. The measures also significantly increased the trust reposed by headquarters in the global team.

The team was also able to overcome the challenge of increasing complexity. This was reflected in the extraordinary performance improvement realized by the team.

Within a year, the predictability and quality of software delivered had significantly improved. The team realized all cross-cutting features involving multiple Scrum teams, and subsystems were delivered on-time, with high quality. The post code freeze defects reduced by $50 \%$. The test execution time reduced by $30 \%$. First pass percentage of automated tests doubled. 
"The best quality we ever had" was the general consensus about the most recent release, which best summarizes the extent of improvement.

Since there were no roles without delivery responsibility every team member was fully invested in meeting the project commitments.

In terms of process maturity, all teams were meeting the stricter quality criteria at the end of each sprint. More importantly, team members were not required to stretch as before, to meet the monthly sprint goals. In short, releases became a non-event.

\section{Lessons learned}

In the course of this journey, we learned several significant lessons which are summarized below.

1. Increase in complexity can decrease trust within a globally distributed software engineering team.

2. The swiftness with which trust decreases is faster than the drop in performance. So, when performance of a global team starts to continually drop, it is worthwhile to assess and reinforce trust.

3. To deliver high quality it is important to identify and address dysfunctions within the teams.

4. To foster trust requires managers and senior members of the team to be vulnerable and creating a circle of safety helps to do this.

5. Creating shared vision establishes a sense of belonging that encourages teams to work together for a common goal. It also fosters a sense of safety, which helps dismantle thinking in silos.

6. Scorecards enable teams to know the overall progress continually, which helps drive results.

7. The lack of accountability in team members may be due to systemic issues such as role definition and lack of training to bridge a capability gap.

8. Real accountability is when team members feel accountable for each other.

9. Trust is the catalyst for any transformation and significant improvement.

\section{REFERENCES}

[1] Daniel . Pink, 2009, Riverhead Books, New York, NY 10014-3672

[2] Simon Snek, 2019, Leaders Eat Last, Penguin Random House, UK

[3] Peter Sege, 2006, The Fifth Discipline, Doubleday, a division of Random House, Inc

[4] Simon Sinek, 2009, Start with Why, Penguin Random House, UK

[5] Patrick Lencioni, 2002, The Five Dysfunctions of a Team

[6] Ray Dalio, 2017, Principles, Simon \& Schuster, New York, NY 10020

[7] Eliyaho M. Goldratt, 2011, The Goal, $20^{\text {th }}$ Anniversary Edition, Productivity \& Quality Publishing Private Limited, T Nagar, Madra

[8] Fahad Usmani, 2019. Projectized organization structure https://pmstudycircle.com/2012/08/what-is-a-projectized-organizationstructure/

[9] Alexander Todorov, November 2017, 4 Situational Leadership Styles http://atodorov.org/blog/2017/11/11/4-situational-leadership-styles/

[10] Cummings, L.L., and Bromiley. P. The organizational trust inventory (OTI): development and validation.

[11] Is Anybody Out There? Antecedents of Trust in Global Virtual Teams, Sirkka L. Jarvenpaa, Kathleen Knoll, and Dorothy E. Leidner, Journal of Management Information Systems / Spring 1998, Vol. 14. No. 4, pp, 29-64

[12] The Decision to Trust, Robert F. Hurley, Harvard Business Review, September 2006

[13] Patrick Lencioni, 2015, Overcoming The Five Dysfunctions of a Team 